\title{
Influence of Heat Control on Welding Stresses in Multilayer-component Welds of High-strength Steel S960QL
}

\author{
Dirk Schroepfer ${ }^{1, a^{*}}$, Thomas Kannengiesser ${ }^{1, b}$ and Arne Kromm ${ }^{1, c}$ \\ 1BAM Federal Institute for Materials Research and Testing, Berlin, Germany \\ adirk.schroepfer@bam.de, bthomas.kannengiesser@bam.de, carne.kromm@bam.de
}

Keywords: High-strength Steel, Welding, Reaction Stress, X-ray diffraction

Abstract. Today high-strength structural steels (yield strength $\geq 960 \mathrm{MPa}$ ) are increasingly applied. Therefore, weldments have to achieve equal strength. Yet, high residual stresses in those welds diminish the components safety. Especially high restraint intensities can lead to crack-critical stresslevels. A special 2-MN-test facility allowed online-measurements of global reaction forces under defined restraint conditions during welding and cooling of multilayer-component MAG-welds. Local residual stresses were measured via X-ray diffraction before and after relief of the restraint. Local and global stresses were highly affected by heat control.

\section{Introduction}

In modern steel constructions more often high-strength steels are required to provide higher energy and cost efficiencies. Therefore, in the recent years steel producers developed various highstrength base materials and filler metals. As a result of the increasing material strength a slender design of components and moreover substantial material and weight savings are possible [1]. Whereas the requirements to the mechanical properties of the weld increase, the demands on the component safety are becoming increasingly important. To ensure the metallurgical requirements, a defined working range regarding the heat control must be maintained. Thus, an appropriate heat control provides the required micro structure properties and a sufficient hydrogen effusion as well as the avoidance of any crack initiations. For that purpose a convenient indicator, the cooling time from $800{ }^{\circ} \mathrm{C}$ to $500{ }^{\circ} \mathrm{C}$ ( $\Delta t_{8 / 5}$-cooling time), was established and generally accepted [2]. Various empirical approaches, nomograms e.g. based on the carbon equivalent and weld tests are available to evaluate a proper heat control [3]. High residual stresses are another contributor for crack initiating. Hence, a reduction and forecast of welding stresses should also be considered, especially for high strength steels. For an adequate heat control before, during and after welding, a better understanding about the interaction between heat control, material and restraint of the surrounding structures is necessary. However, most of recent research activities concerned with residual stress characteristics in welds of free shrinking laboratory samples, disregarding supporting effects and heat conduction terms of real component structures [4,5]. Several numerical and experimental studies revealed a high effect of restraint intensity and component dimensions on reaction stresses in welded structures [6-9]. These works conclude a superposition of local residual stresses and global reaction stresses due to restraint, cp. Fig. 1. Therein, the global restraint strongly affects the amplitude of the weld seams residual stress maxima and results in higher stress levels.

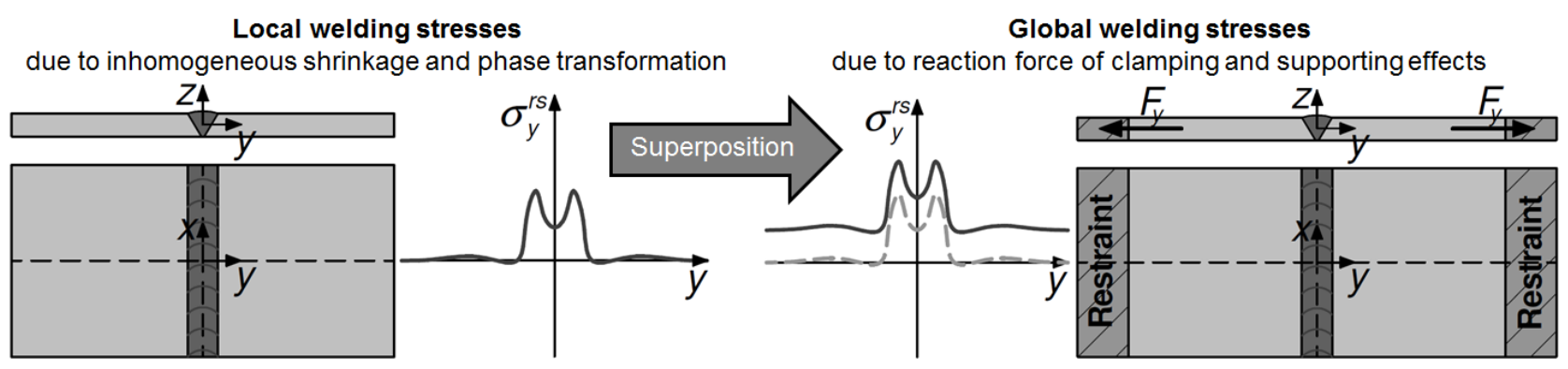

Fig. 1. Welding stresses as a result of local and global restraint [6]. 
Furthermore, several recent analyses [10-12] involved the interaction between heat control and stress build-up in welds under global restraint. A strong influence of preheat and interpass temperature on the resulting reaction forces was found. However, expected welding stresses are usually considered by global safety factors in existing standards and technical guidelines. Continuative studies for an improved knowledge regarding stress forecast and reduction in high strength steel component welds are absent yet. Therefore, this present work analyses the effect of heat control on welding stresses considering realistic restraint conditions by a special test facility.

\section{Experimental}

Test Material. Plates of high strength quenched and tempered fine grained structural steel S960QL with a thickness of $20 \mathrm{~mm}$ were welded. A similar high strength solid wire according to ISO 16834 was used as filler metal. To provide a crack free root layer an undermatching weld metal was used. The chemical composition and mechanical properties are given in Table 1 and Table 2.

Table 1. Chemical compositions of test materials (spark emission spectroscopy, Fe balanced).

\begin{tabular}{ccccccccccccc} 
Element [\%] & $\mathrm{C}$ & $\mathrm{Si}$ & $\mathrm{Mn}$ & $\mathrm{B}$ & $\mathrm{Cr}$ & $\mathrm{Cu}$ & $\mathrm{Mo}$ & $\mathrm{Nb}$ & $\mathrm{V}$ & $\mathrm{Ni}$ & $\mathrm{Ti}$ \\
\hline Base material (a) & 0.12 & 0.22 & 1.25 & 0.0004 & 0.20 & 0.01 & 0.58 & 0.015 & 0.040 & 0.053 & 0.01 \\
Filler material (b) & 0.11 & 0.71 & 1.47 & 0.0010 & 0.35 & 0.11 & 0.62 & 0.001 & 0.002 & 2.21 & 0.03 \\
Filler material, root (c) & 0.07 & 0.84 & 1.43 & 0.0005 & 0.10 & 0.10 & 0.02 & 0.005 & 0.009 & 0.07 & 0.01
\end{tabular}

(a) EN 10025-6 S960QL, (b) EN ISO 16834 -A-G 896 M Mn4Ni2CrMo, (c) EN ISO 14341-A-G 464 M21 4Si1

Table 2. Mechanical properties of the test materials (mechanical testing (a), producer test report $(\mathrm{b}, \mathrm{c})$ ).

\begin{tabular}{ccccccc} 
Property & $R_{p 0.2}[\mathrm{MPa}]$ & $R_{m}[\mathrm{MPa}]$ & $A_{5}[\%]$ & $Z[\%]$ & $A v$ at $-40{ }^{\circ} \mathrm{C}[\mathrm{J}]$ & Hardness [HV10] \\
\hline Base material (a) & 989 & 1036 & 17 & - & 139 & 340 \\
Filler material (b) & 954 & 1024 & 15 & 41 & 52 & 345 \\
Filler material, root (c) & 530 & 612 & 26 & 64 & 81 & 199
\end{tabular}

(a) EN 10025-6 S960QL, (b) EN ISO 16834-A-G 896 M Mn4Ni2CrMo, (c) EN ISO 14341-A-G 464 M21 4Si1

Weld Process and Parameters. All welds were performed with an automated MAG multilayerwelding process. The welding parameters are shown in Table 3 . The heat control was varied by means of interpass temperature $T_{i}$, cp. Table 4 . Regarding production relevant process conditions, the $\Delta t_{8 / 5}$-cooling times were considered while selecting these parameters and determined for each specific weld test. The achieved $\Delta t_{8 / 5}$-cooling times comply the producer specifications, cp. Table 4 .

Table 3. Welding parameters.

\begin{tabular}{cccccccc}
$\begin{array}{c}\text { Weld } \\
\text { preparation }\end{array}$ & $\begin{array}{c}\text { Welding } \\
\text { current }[\mathrm{A}]\end{array}$ & $\begin{array}{c}\text { Welding } \\
\text { voltage }[\mathrm{V}]\end{array}$ & $\begin{array}{c}\text { Welding speed } \\
{[\mathrm{mm} / \mathrm{min}]}\end{array}$ & $\begin{array}{c}\text { Wire feed } \\
\text { speed }[\mathrm{m} / \mathrm{min}]\end{array}$ & $\begin{array}{c}\text { Shielding gas } \\
-\end{array}$ & $\begin{array}{c}\text { Preheat tem- } \\
\text { perature }\left[{ }^{\circ} \mathrm{C}\right]\end{array}$ & $\begin{array}{c}\text { Heat input } \\
{[\mathrm{kJ} / \mathrm{mm}]}\end{array}$ \\
\hline V groove, $45^{\circ}$ & $225 \pm 10$ & $24.5 \pm 1$ & 310 to 370 & 6.5 to 7 & EN ISO 14175:M21 & 120 & 0.95
\end{tabular}

Table 4. Variation of heat control and restraint condition in connection with the $\Delta t_{8 / 5}$-cooling times.

\begin{tabular}{cccccc}
\multicolumn{2}{c}{ Test no. } & & 1 & 2 & 3 \\
\hline Interpass temperature & $T_{i}$ & {$\left[{ }^{\circ} \mathrm{C}\right]$} & 200 & 200 & 100 \\
Restraint intensity & $R_{F y}$ & {$[\mathrm{kN} /(\mathrm{mm} \cdot \mathrm{mm})]$} & 0 & 3 & 3 \\
Measured cooling time & $\Delta t_{8 / 5}$ & {$[\mathrm{~s}]$} & 7 & 7 & 6
\end{tabular}
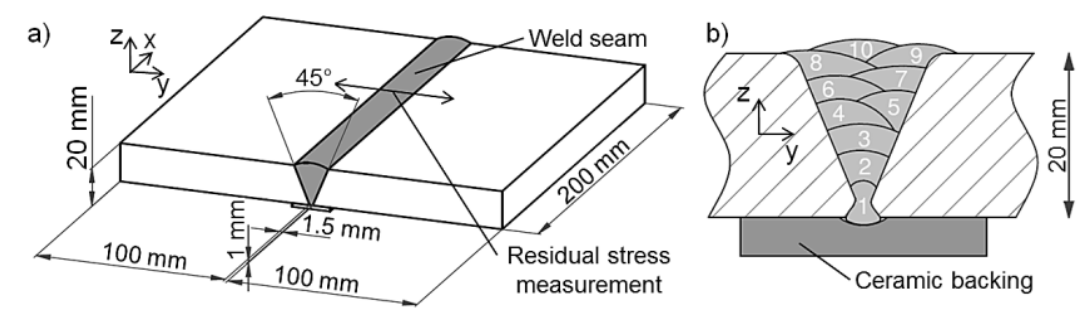

Fig. 2. a) Specimen dimensions for the free shrinking weld test, b) Build-up sequence. 
Weld Tests and Dimensions. A free shrinking test specimen was welded to get a reference for residual stress and weld properties. Fig. 2 shows the specimen dimensions and build-up sequence of the weld tests. An implementation of defined restraint intensity during welding and cooling was accomplished with a special in-house developed 2-MN-test facility. The restraint intensity in weld transverse direction $R_{F y}$ is the components stiffness towards the weld seam related to the seam length. For simple butt joints it can be estimated according to [13]. Realistic restraint conditions of $R_{F y}=3 \mathrm{kN} /(\mathrm{mm} \cdot \mathrm{mm})$ in transverse direction were realized. Therefore test specimens were clamped into the 2-MN-test facility, cp. Fig. 3. Run on-/off plates were tack welded to one side of the specimen couple to minimise influences of instable arc conditions during ignition and shut-off.

a)
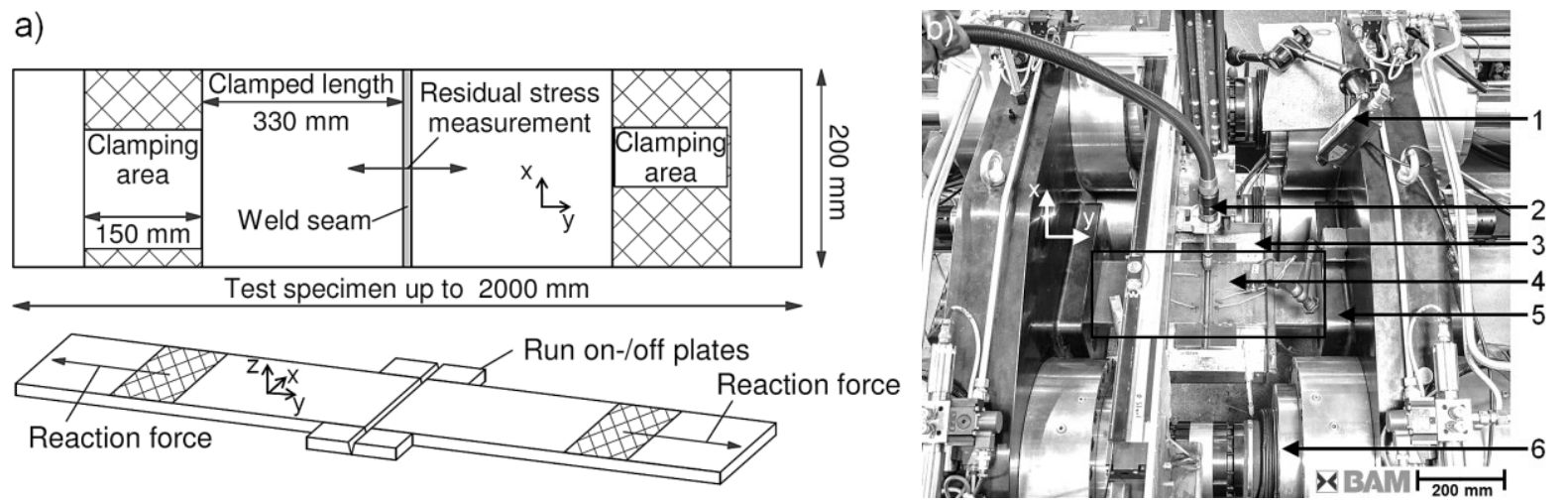

Fig. 3. a) Specimen dimensions for component weld tests, b) Test-setup for 2-MN-test facility, 1. Two colour pyrometer ( $\Delta t_{8 / 5}$-time determination), 2. MAG-torch, 3. Heating mat (preheating and interpass temperature),

4. Test specimen with type-K-thermocouples, 5. Cross head (clamping device), 6. Hydraulic cylinders.

Measurements. To monitor preheat and interpass temperatures type- $\mathrm{K}$ thermo couples were attached $10 \mathrm{~mm}$ adjacent to the weld. Additionally, the interpass temperature was observed with a contact thermocouple on the weld seam. $\Delta t_{8 / 5}$-cooling times were determined by an optical temperature measurement at the weld layer surface using a two colour pyrometer (measuring range: $350{ }^{\circ} \mathrm{C}$ to $1300{ }^{\circ} \mathrm{C}$ ). Using the test facility an online-measurement of the reaction forces due to restraint was achievable. Those forces and temperatures were observed while preheating, welding and subsequent cooling to ambient temperature. In the weld local transverse residual stresses were determined via X-ray diffraction using the $\sin ^{2} \psi$-method on the top surface after cooling to ambient temperature. These measurements were performed before and after stress relief of the restraint.

\section{Results}

Global Reaction Stress. Fig. 4a shows the reaction force $F_{y}(t)$ and temperature $T(t)$ for test no. 2, $\mathrm{cp}$. Table 4. At the beginning of the root weld the reaction force is $-82 \mathrm{kN}$, since preheating of the tack welded specimen initiates a compressive force. During welding of the root a force build-up is obvious due to shrinkage of the already solidified inserted weld metal, which generates transversal shrinking forces. While the root weld is cooling down to interpass temperature the reaction force is increasing further with a first maximum of $F_{y}=121 \mathrm{kN}$ at $T_{i}=100^{\circ} \mathrm{C}$. A force reduction was detected while welding the next layer, since a local heat input combined with stress relief and partial fusion of the root occurs. Subsequent cooling to $T_{i}$ leads to a new continuous increasing of the reaction force and the next weld run to a force reduction. This force evolution with an increase of the force amplitude was observed for every weld sequence. The amplitude of the force reduction is the result of welding heat input and rises with each layer. Likewise, the reaction force build-up during cooling to interpass temperature grows with every weld sequence. After the completion of the weld and subsequent cooling to ambient temperature a maximum reaction force of $F_{y, \text { end }}=398 \mathrm{kN}$ is reached. In Fig. $4 \mathrm{~b}$ reaction forces $F_{y}(t)$ for 2-MN-test welds with interpass temperatures of $T_{i}=100{ }^{\circ} \mathrm{C}$ and $T_{i}=200{ }^{\circ} \mathrm{C}$ are shown. Whereas the two $F_{y}(t)$-graphs exhibit the same tendency, a reduction of total welding time by $35 \%$ using a high interpass temperature $\left(T_{i}=200^{\circ} \mathrm{C}\right)$ is obvious. The comparison of the force amplitudes reveals a lower level for the 
higher interpass temperature due to shorter cooling cycles. A higher heat level thereby remains between each weld run and leads to a lower decrease of the transvers shrinking forces at each pass. At the last weld run the reaction force is half as high compared to weld including lower interpass temperature. After cooling to ambient temperature a remarkable increase of the reaction force for the higher interpass temperature occurs, since the specimen contains a distinct higher heat quantity. The resulting end reaction stress $\sigma_{y, \text { end }}$ is about $30 \%$ higher for $T_{i}=200{ }^{\circ} \mathrm{C}$, cp. Fig. $4 \mathrm{~b}$ and Fig. $7 \mathrm{~b}$.
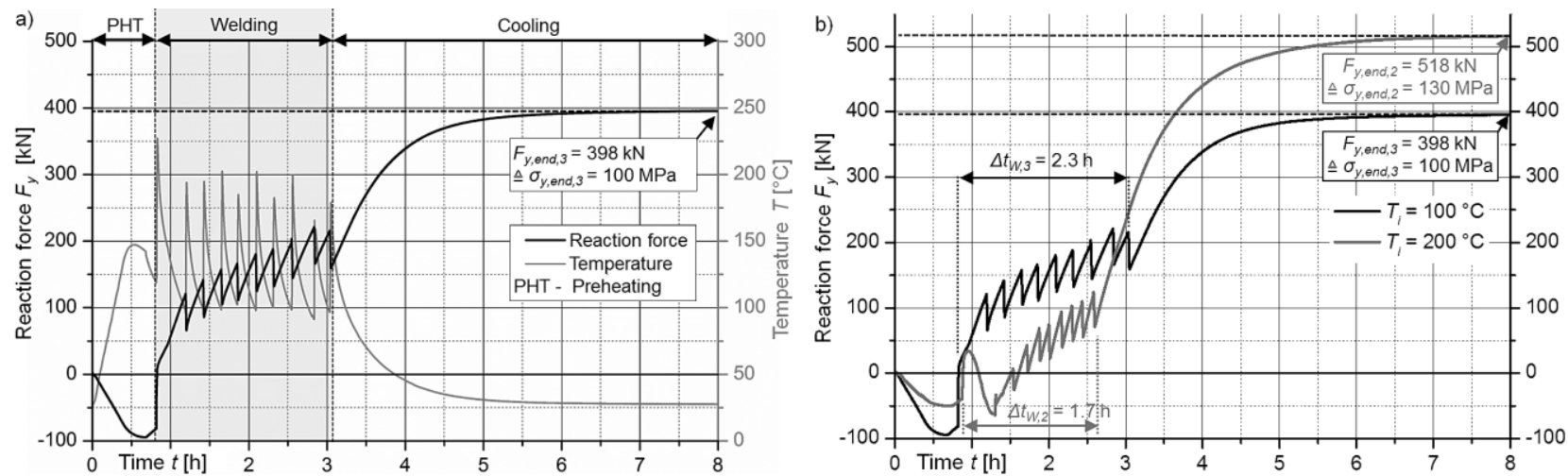

Fig. 4. a) Reaction force $F_{y}(t)$ and temperature $T(t)$ for weld test no. $3\left(T_{i}=100^{\circ} \mathrm{C}\right)$, b) comparison of reaction force graphs $F_{y}(t)$ for two different interpass temperatures $T_{i}$.

Local Residual Stress. Fig. 5a presents the transversal residual stress distributions across the weld for two different restraint conditions at the centre line $(x=0 \mathrm{~mm})$ of the specimen. Both graphs show characteristic residual stress distributions for steels including phase transformation according to the common concepts [14]. Tensile residual stress maxima occur next to the weld centre line of the last weld run and side peaks at the weld metal next to the fusion line. In each weld run centre stress dips occur due to transformation. The tensile residual stress maximum of $650 \mathrm{MPa}$ ( $70 \%$ of $R_{p 0.2}$ of the weld metal) and the overall stress level tends to be higher with global restraint applied. The average transverse residual stresses $\sigma_{y, \text { avg }}^{r s}$ in the weld $\left(y_{l}=-20 \mathrm{~mm}\right.$ to $\left.y_{2}=20 \mathrm{~mm}\right)$ are about $80 \%$ higher compared to the free shrinking specimen, cp. Eq. 1 and Fig. 5b.

$$
\sigma_{y, a v g}^{r s}\left(y_{1} \ldots y_{2}\right)=\left(1 /\left(y_{2}-y_{1}\right)\right) \int_{y_{1}}^{y_{2}} \sigma_{y}^{r s}(y) d y
$$
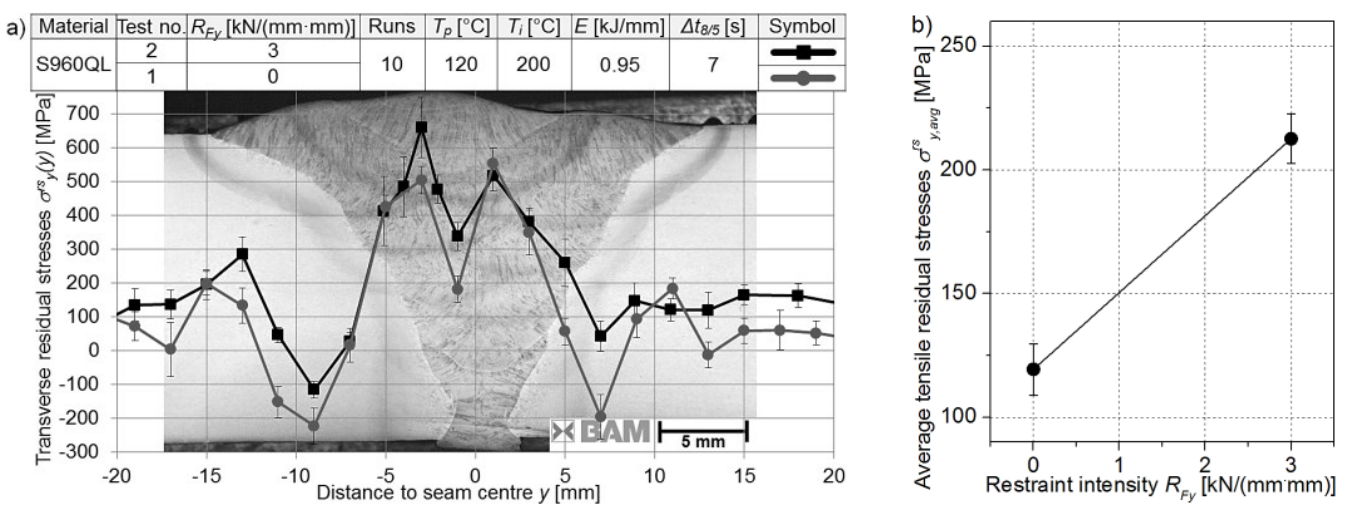

Fig. 5. Comparison of a) two transverse residual stress distributions $\sigma_{y}^{r s}(y)$ for different restraint conditions, b) two resulting average transverse residual stress values $\sigma_{y, \text { avg }}^{r s}(y=-20 \mathrm{~mm}$ to $20 \mathrm{~mm})$ as a function of the restraint intensity $R_{F y}$.

In Fig. 6a two transverse residual stress distributions for different interpass temperatures at restrained condition are compared. The tensile stress peaks and levels tend to be higher when a higher interpass temperature is used. One reason is the increased temperature level of the weld while the top layer is welded due to shorter cooling cycles. Therefore, subsequent cooling to ambient temperature increases the inhomogeneous shrinkage restraint in the weld area and involves a higher corresponding tensile stress initiation. Comparing the resulting average transverse residual 
stress values $\sigma_{y \text {,avg }}^{r s}$ an interpass temperature variation from $T_{i}=200{ }^{\circ} \mathrm{C}$ to $100{ }^{\circ} \mathrm{C}$ leads to reduction of about $20 \%$, cp. Fig. 6b. Another reason for this effect is described by the superposition of global reaction stresses as discussed in the next section.
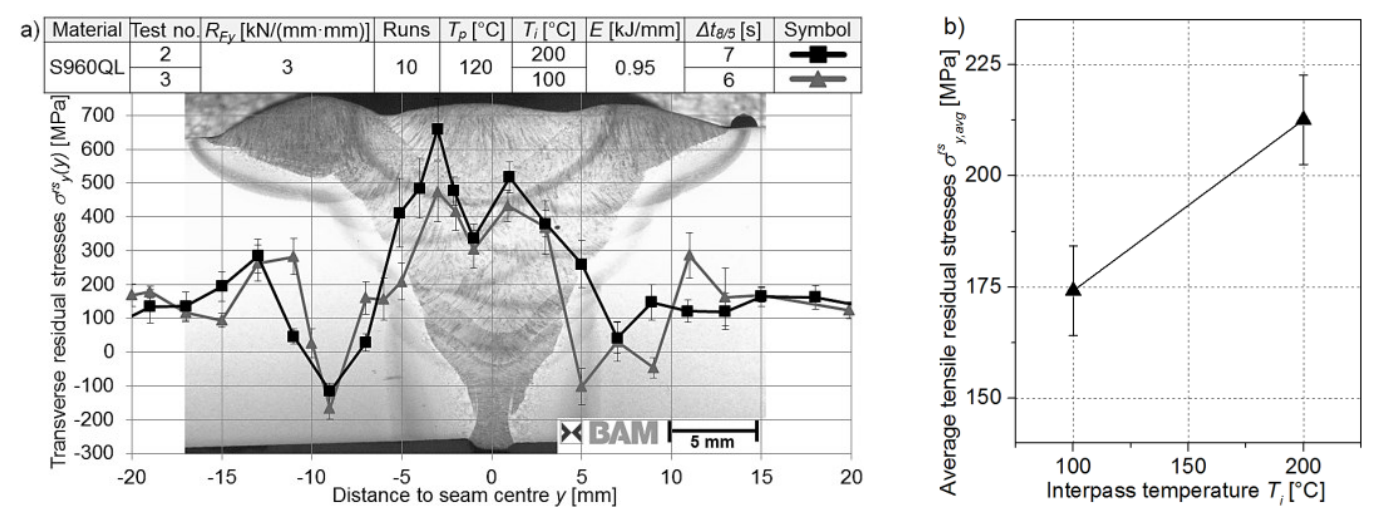

Fig. 6. Comparison of a) two transverse residual stress distributions $\sigma^{r s} y(y)$ for different interpass temperatures $T_{i}$ (restraint), b) resulting average transverse residual stresses $\sigma^{r s}{ }_{y, a v g}$ as a function of $T_{i}$.

Stress Relief. Fig. 7a presents a comparison of transverse residual stress distributions before and after the stress relief of the restraint of test no. 2. The stress relief leads to an almost parallel shift of the transverse residual stress distribution. The estimated difference between the average transverse stress before and after stress relief revealed to be nearly the same as the determined end reaction stress with ca. $115 \mathrm{MPa}$ for $T_{i}=200^{\circ} \mathrm{C}$, cp. Fig. $7 \mathrm{~b}$.
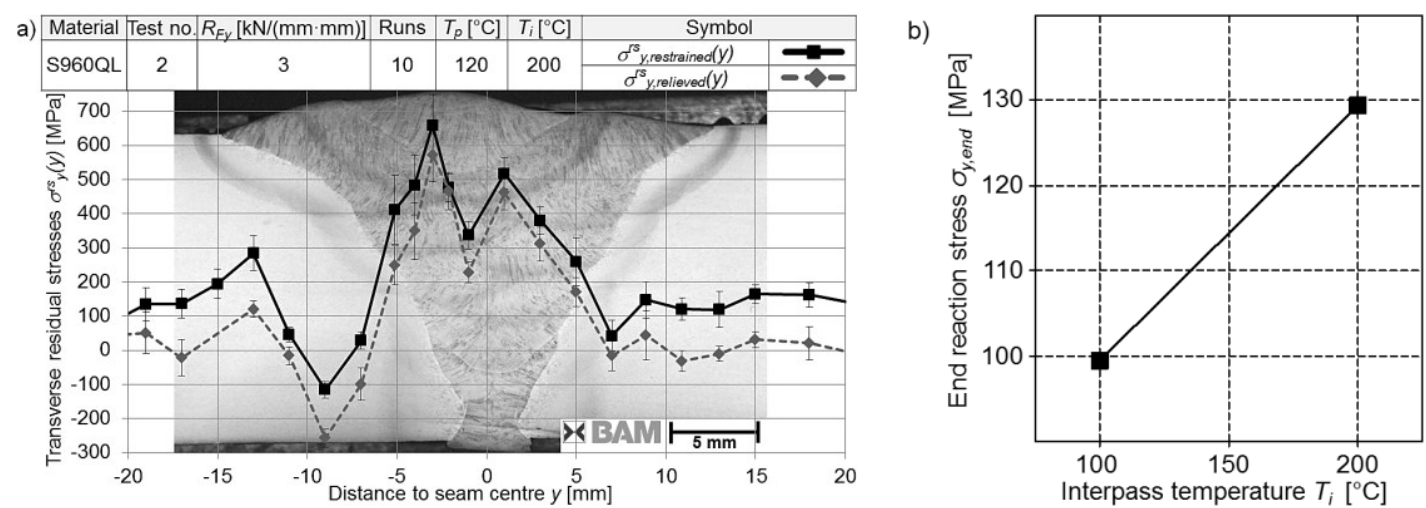

Fig. 7. Comparison of a) transverse residual stress distributions $\sigma^{r s} y(y)$ before and after stress relief of the restraint, b) end reaction stresses $\sigma_{y, \text { end }}$ as a function of interpass temperature $T_{i}$.

\section{Summary}

In the present study, the influence of heat control on welding stresses in high-strength steel component was analysed. Plates of $20 \mathrm{~mm}$ thickness were multilayer-MAG-welded under free shrinkage and defined restraint conditions. The interpass temperature was varied between $100{ }^{\circ} \mathrm{C}$ and $200{ }^{\circ} \mathrm{C}$. Online-measurements allowed an observation of the occurring reaction forces while welding and cooling. The local residual stress determination was performed using X-ray diffraction at weld test specimen. From this work, the following conclusions can be drawn:

- The heat control significantly affects the reaction stress. Reaction force amplitudes increase with each run during the welding process and are obviously lower with higher interpass temperatures.

- However, low interpass temperatures lead to reduced reaction stress after subsequent cooling in accordance to recent studies [10-12].

- In this work a first quantification of this effect was accomplished for high strength steel components of S960QL.

- Based on extensive recent studies concerned with the influence of heat control on reaction stresses under restraint conditions $[11,12]$ in this work local welding stresses were involved. 
- With a new approach of average transverse residual stresses influences of heat control and restraint condition on these stresses were analysed. Therefore, a comparison of total welding stresses of specimens welded under restraint and free shrinkage was achieved.

- The superposition of global and local welding stresses leads to higher residual stress levels under restraint conditions. The increase of average transverse residual stresses by approximately $100 \mathrm{MPa}$ is almost equal to the resulting reaction stress.

- Moreover, an adapted heat control revealed to be a sufficient way to lower average tensile residual stresses by more than $20 \%$.

- The local residual stress determination after stress relief revealed an almost parallel shift in the range of the measured reaction stress.

\section{Acknowledgements}

The studies were funded by the AiF-project IGF-Nr. 17267 N / FOSTA P922. Sincere thanks are given for this support and to the representing companies actively involved in the project board.

\section{References}

[1] M. Klein, H. Spindler et al., Thermomechanically Hot Rolled High and Ultra High Strength Steel Grades - Processing, Properties and Application, Mater. Sci. Forum, 500-501 (2005) 543550.

[2] O. Grong, Metallurgical Modelling of Welding, Institute of Materials, 1997.

[3] EN 1011-2: Welding - Recommendation for Welding of Metallic Materials - Part 2: Arc welding of ferritic steels, 2001.

[4] K. Satoh, Restraint Stresses/ Strains v. Cold Cracking in RRC Test of High Strength Steel, in: Proceedings, Conference on "Residual Stresses in Welded Construction and their Effects", London, 1977, pp. 283-289.

[5] P. Wongpanya, T. Boellinghaus, Residual Stress Distribution in Competing S 1100 QL ButtWelds Dependent on Plate Thickness and Restraint Length, in: Proceedings, Conference on "High Strength Steels for Hydropower Plants", Takasaki, 2009.

[6] T. Boellinghaus, T. Kannengiesser, M. Neuhaus, Effects of the Structural Restraint Intensity on the Stress Strain Build Up in Butt Joints, Mathematical Modelling of Weld Phenomena 7 (2005), 651-669.

[7] W. Jiang, X.P. Xu, J.M. Gong, S.T. Tu, Influence of Repair Length on Residual Stress in the Repair Weld of a Clad Plate, Nuncl. Eng. Des. 246 (2012) 211-219.

[8] M. Hirohata; Y. Itoh, Effect of Restraint on Residual Stress Generated by Butt-welding for Thin Steel Plates, in: Proceedings, "9th German-Japanese Bridge Symposium", Kyoto, 2012.

[9] P. Dong; J.K. Hong; P.J. Bouchard, Analysis of Residual Stresses at Weld Repairs, Int. J. Pres. Ves. Pip.82 (2005) 258-269.

[10]D. Schroepfer, T. Kannengiesser, T. Lausch, Investigations of the Influence of Heat Control on the Residual Stress Build-up and Overall Stress in Welded Joints of High-strength Fine-grained Structural Steel, DVS Berichte 296 (2013) 339-345 (in German).

[11] T. Lausch, T. Kannengiesser, M. Schmitz-Niederau, Multi-Axial Load Analysis of ThickWalled Component Welds Made of 13CrMoV9-10, J. Mater. Process. Tech. 213 (2013) 12341240.

[12]T. Kannengiesser, T. Lausch, A. Kromm, Effects of Heat Control on the Stress Build-up During High-strength Steel Welding under Defined Restraint Conditions, Weld. World 55 (2011) 58-65.

[13]K. Satoh, Y. Ueda, S. Matsui et al., Tsuji: Japanese Studies on Structural Restraint Severity in Relation to Weld Cracking, Weld. World 15 (1977) 155-189.

[14]T. Nitschke-Pagel, H. Wohlfahrt, Residual Stresses in Welded Joints - Sources and Consequences, Mater. Sci. Forum 404-407 (2002) 215-226. 